\title{
Análise da espessura e flexão de matrizes pelo método dos elementos finitos
}

\author{
Matrix thickness and bending analysis by finite element method
}

Evalderico José Silveira ${ }^{1 *}$, Prof. Dr. Marcelo Sampaio Martins ${ }^{2}$

\begin{abstract}
RESUMO
As chamadas Matrizes de Corte estão presentes em grande parte da indústria global devido à sua funcionalidade eo custo de produção dos produtos dela oriundos. Deste modo, a realização de Projetos de Ferramentas de Corte, como furação, dobra e repuxo, demanda do seu correto dimensionamento levando em considerações as condições de contorno inerentes à cada operação. O rompimento ou rupturas destas Matrizes durante o processo de produção causam paradas não programadas, com possíveis atrasos de entregas ao cliente, manutenções corretivas por vezes inadequadas, dentre outras. Trata-se, portanto, de um estudo comparativo, cujo objetivo principal é o de análise da espessura da matriz análoga e a obtida computacionalmente via FEM para posteriores aplicações em matrizes que estão em operação (fisicamente disponível na empresa Metalúrgica Caser), mantendo o mesmo ciclo de vida. Por fim, a análise dos resultados obtidos do modo analítico em literatura específica da área abordada, com o computacional por meio de simulação.
\end{abstract}

Palavras-chave: Estampagem; Estampos; Matriz; Ferramentas de corte; Método dos Elementos Finitos.

\begin{abstract}
The so-called Cutting Dies are present in a large part of the global industry due to their functionality and the cost of production of the products originated from them. Thus, the realization of Cutting Tool Projects, such as drilling, bending and drawing, requires their correct dimensioning, taking into account the boundary conditions inherent to each operation. The breakage or ruptures of these dies during the production process cause unscheduled shutdowns, with possible delays in deliveries to the customer, corrective maintenance sometimes inadequate, among others. It is, therefore, a comparative study, whose main objective is to analyze the thickness of the analogous matrix and that obtained computationally via FEM for further applications in matrices that are in operation (physically available at the company Metalúrgica Caser), keeping the same life cycle. Finally, the analysis of the results obtained in the analytical way in the specific literature of the approached area, with the computational one through simulation.
\end{abstract}

Keywords: [Stamping; Stamps; Headquarters; Cutting tools; Finite Element Method.]

\footnotetext{
${ }^{1}$ Universidade de Taubaté, *E-mail: evalderico@hotmail.com

${ }^{2}$ Universidade de Taubaté, *E-mail: sampaio.martins@unesp.br
} 


\section{INTRODUÇÃO}

O processo de estampagem esta caracterizado por sua alta produtividade, repetitividade dimensional, entretanto, para que as vantagens inerentes deste processo se sobressaiam, o processo deve possuir disponibilidades suficientes (vertente do prazo de entrega), adequação funcional (dimensional e de carregamento, como vertente de qualidade) à operação e baixo custo relativo (com vertente de defesa), com vistas a evitar a realização de testes com protótipos e produtos, o processo de Projeto pode contemplar a simulação computacional.

A referida analise da flexão e espessura da matriz é estudada e obtida por meio de uma problematização de verificação e utilizando o Método dos Elementos Finitos (MEF) com o auxílio da ferramenta computacional ANSYS®.

Este trabalho tem como objetivo análise sobre os cálculos numéricos e a simulação computacional em detrimento da Matriz de corte utilizando-se de um modelo virtual como Matriz didática, assegurando a confiabilidade da relação em projetos futuros por empresas do setor e afins.

\section{RESULTADOS}

Os resultados obtidos com os cálculos analíticos referente a espessura da Matriz foram bem validados em relação a simulação computacional, dando toda a segurança possível para a determinação da espessura.

A força exercida pela Prensa, têm em suas variáveis oriundas da Resistência ao Cisalhamento sofrido na espessura da chapa juntamente seu perímetro, onde pode provocar a flexão e posteriormente a trinca ou quebra.

Para este trabalho utilizou-se da chapa SAE-1020 com espessura de 2,50mm, cuja sua resistência a tração oscila entre $350 \mathrm{MPa}$ à $420 \mathrm{MPa}$ e para o limite de cisalhamento entre $260 \mathrm{MPa}$ à $320 \mathrm{MPa}$, onde encontramos valores para a folga de corte que variam de 0,07mm para uma aplicação mais precisa e 0,20mm para uma aplicação comum.

Seguindo com a espessura da Matriz, seus cálculos analíticos aplicados a deslocamentos por deflexão em torno de $0,072 \mathrm{~mm}$ a $0,079 \mathrm{~mm}$, porem quando a analise sugere reduzir a distância de vão dos apoios abaixo da matriz, esse deslocamento gira em torno de 0,0073mm um número bem próximo do resultado obtido com a equação da linha elástica que neste estudo trata a lateral da de corte da matriz como uma viga que foi da ordem de $0,0081 \mathrm{~mm}$.

Quando observamos a Tensão de Von Mises, mesmo não adequada para aplicação em materiais frágeis, o software entrega os valores das tensões Máxima, Média e Mínima, onde o resultado obtido foi a Tensão Equivalente Von Mises, que segundo o método numérico está em 202,62 MPa enquanto a simulação sendo a Tensão inferior e sua máxima de 280,69 MPa, nos induz a confiabilidade do cálculo da espessura devido a Tensão Limite de Escoamento estar próxima de 208,82 MPa. 
Por análise entre o computacional eo numérico os valores dos deslocamentos elásticos resultaram bem próximos, entre $0,0016 \mathrm{~mm}$ para o numérico e $0,0014 \mathrm{~mm}$ para o computacional, números também inferiores as deformações por deflexões.

A deformação total com forças aplicadas no cume de corte, demonstram uma máxima deformação de $0,0133 \mathrm{~mm}$, esta deformação uma vez analisada com outras deformações de deflexões pelo método numérico, mostra ser muito inferior aos resultados obtidos que estão na ordem média de $0,076 \mathrm{~mm}$ considerando a matriz com apoio simples.

Para averiguação do valor 77,68 MPa, uma vez que as variáves de entrada utilizadas no software foram de 202,8 GPa para o Módulo de Rigidez e 78 GPa para o Módulo de Cisalhamento eo Coeficiente de Poisson 0,30, pode-se aferir o valor do coeficiente dividindo o cisalhamento pela rigidez onde verificou-se um valor 0,38 .

Para deformações direcionais a direção em y demonstra a Matriz levemente vulnerável à vista do cálculo numérico, sendo esta região da Matriz tratada como viga através da linha neutra eo resultado encontrado de $0,0081 \mathrm{~mm}$, próximo de $0,0108 \mathrm{~mm}$ da simulação.

\section{FOLGA DE CORTE}

Para uma analise da deflexão de uma matriz, a carga recebida durante seu cisalhamento é chamado de esforço de corte, este esforço esta diretamente ligado pela folga de corte.

A folga ideal, sendo que a Resistência ao Cisalhamento da chapa foi utilizada como sendo $75 \%$ da Tensão de Tração (418 MPa), uma vez que para o aço SAE 1020 utilizamos $313,81 \mathrm{MPa}$ ou $313,81 \mathrm{~N} / \mathrm{mm}^{2}$.

A diferença numérica do conceito entre preciso e pouco preciso, pode ser visto na parede da chapa onde o cisalhamento foi efetivo, quanto mais preciso maior o percentual de superfície lisa enquanto pouco preciso a incidência da superfície lisa ou superfície extrudada ficam menor que os $50 \%$ da espessura da chapa.

Lembrando que folgas excessivas provocam rebarbas enquanto nas peças enquanto que folgas pequenas promovem o desgaste prematuro das arestas de corte, aumentado assim a Força de Corte e reduzindo a via útil do ferramental.

folga por lado $=(C . t.) \cdot \sqrt{\frac{\operatorname{Tmax}}{10}}$

folga por lado $=(0,005.2,5) \cdot \sqrt{\frac{313,81}{10}} \quad$ folga por lado $=0,070 \mathrm{~mm}$
folga por lado $=(0,01.2,5) \cdot \sqrt{\frac{313,81}{10}} \quad$ folga por lado $=0,140 \mathrm{~mm}$

onde:

$C_{1}=0,005$ (constante para componentes precisos) 
$C_{2}=0,010$ (constante para componentes pouco precisos)

$t=$ Espessura da chapa $(\mathrm{mm})$

Tmax $=$ Resistência ao cisalhamento do material $\left(\mathrm{N} / \mathrm{mm}^{2}\right)$

A Folga de Corte interfere diretamente no esforço da Prensa e Matriz, entretanto porém quando não se sabe ao certo a Resistência ao Cisalhamento do material, esta fica em torno de $10 \%$ da espessura da chapa ou seja $5 \%$ por lado; para chapas de até ou menor que $3 \mathrm{~mm}$ $\left(e_{e}\right)$ de espessura.

$\mathrm{Na}$ falta do valor exato de $K s$ (Resistência ao Cisalhamento do material em $\mathrm{Kgf} / \mathrm{mm}^{2}$, também conhecido como Pressão Específica de Corte) pode ser especificado como um valor aproximado de resistência ao cisalhamento com sendo $80 \%$ da tensão de ruptura a tração do material considerado.

$\left.f / 2=\left(0,01 . e_{e}-0,015\right) \cdot \sqrt{ } K s\right)$

$f / 2=0,01 \cdot \sqrt{ } 320$

$f=0,0894 \mathrm{~mm}$

onde:

$f=$ Folga de corte $(\mathrm{mm})$

$e_{e}=$ Espessura da chapa $(\mathrm{mm})$

$K s=80 \%$ da Tensão ruptura ao cisalhamento $\left(\mathrm{N} / \mathrm{mm}^{2}\right)$

\section{ESPESSURA DA MATRIZ}

Pode-se aumentar a vida útil da matriz através de uma folga entre 2,5\% a 5,0\% da espessura do material, onde geralmente a folga de corte da matriz permanece um pouco menor para materiais mais dúcteis.

Considerando as espessura minima de matrizes devem partir próximas de $14 \mathrm{~mm}$., Para ocalculo da espessura da matriz temos.

$E F C=P_{e} \cdot e_{e} \cdot R C$

$E F C=130.2,5.320$

$E F C=104000 \mathrm{~N} / \mathrm{mm}^{2} \approx 10,6 t$

onde:

$E F C=$ Esforço de corte ou cisalhamento $(\mathrm{N})$

$P_{e}=$ Perímetro da figura $(\mathrm{mm})$

$e_{e}=$ Espessura da chapa $(\mathrm{mm})$

$R_{c}=$ Resistência ao cisalhamento do material $\left(\mathrm{N} / \mathrm{mm}^{2}\right)$

A espessura da Matriz está relacionada com a raiz cúbica do esforço de corte, porém a este valor pode acrescer em média de $10 \%$ sobre a sua espessura da matriz encontrada. 
$E M=\sqrt[3]{ } E F C$

$E M=\sqrt[3]{ } 10400$

$E M=21,827 \mathrm{~mm}$

Figura 1. Representação Gráfica do Exemplo Modelo

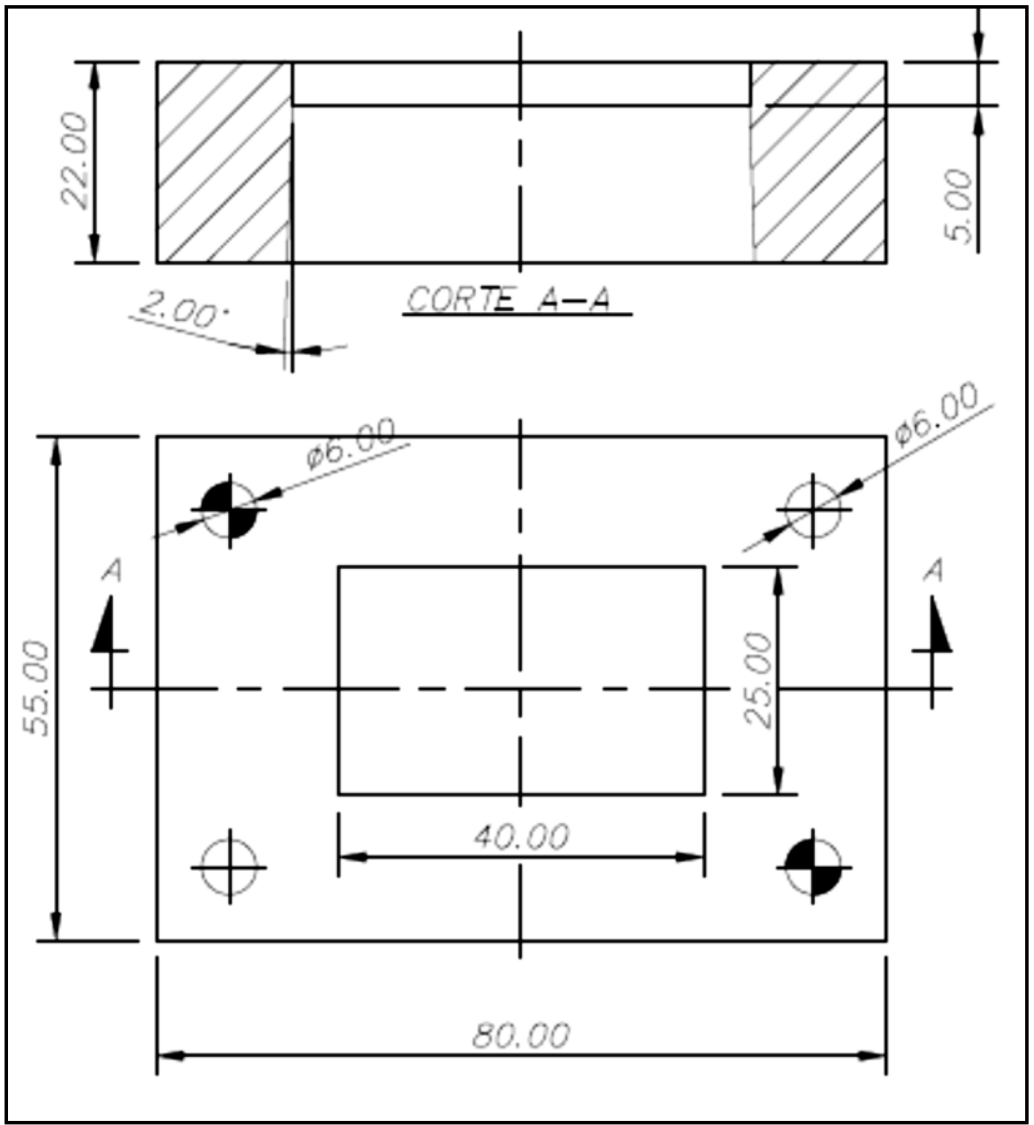

Fonte. O Autor

\section{DEFLEXÃO PELO MÉTODO DALINHA NEUTRA}

Tratando a lateral da matriz como uma viga de duplo engastamento e carga ao centro bi apoiada em pontos A-B conforme a Figura 12, a linha elástica tem sua configuração geométrica no deslocamento vertical dos pontos situados no eixo longitudinal de uma viga, quase sempre representada analiticamente por meio de uma função $y=f(x)$, sendo possível a dedução dessa função a partir de uma equação diferencial ordinária de segundo grau.

Figura 2 - Ilustração da interpretativa Viga / Matriz de Corte. 


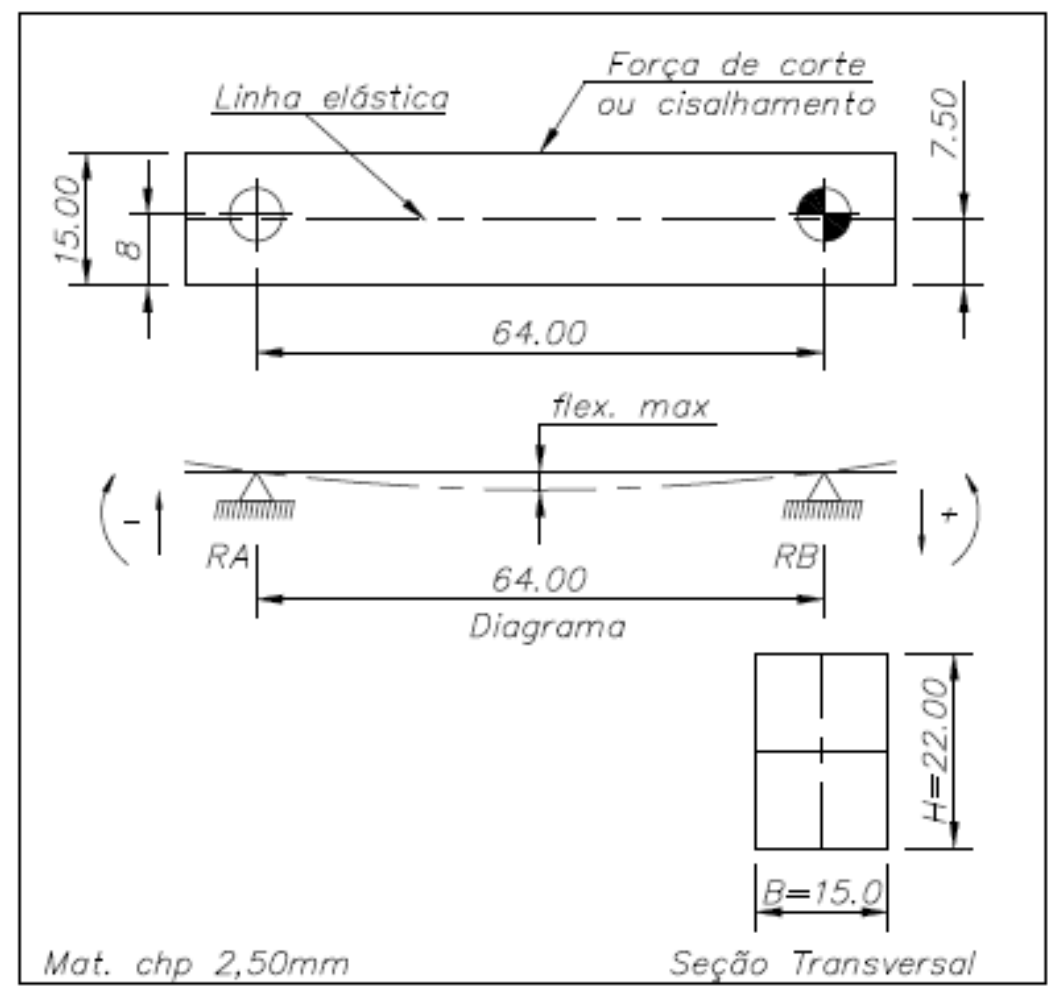

Fonte. Autor

A equação da linha elástica, utilizada na lateral da matriz como a uma viga, temos:.

E. I. $\frac{d^{2} v}{d x^{2}}=M(x)$

onde:

$W=$ Densidade de carga

$V=$ Equação da cortante

$M=$ Equação do momento

Sendo a força aceita como centrada e suas forças de reações f.x verifica-se então:

$\mathrm{Ra}=\frac{1}{2} W L$

$M(x)=+\operatorname{Ra} L_{x}-W \cdot x \cdot \frac{x}{2}$

$M(x)=-\frac{1}{2} w x^{2}+\frac{1}{2} \cdot W L_{x}$

Substituindo a equação (5) na equação (8) com v = y

E. I. $\frac{d^{2} v}{d x^{2}}=M(x) \quad \therefore \quad$ E. I. $\frac{d^{2} y}{d x^{2}}=-\frac{1}{2} w x^{2}+\frac{1}{2} \cdot W L_{x}$

Integrando ambos os lados a primeira vez obtemos o angulo do deslocamento.

$\int$ E. I. $\frac{d^{2} y}{d x^{2}}=\int-\frac{1}{2} w x^{2}+\frac{1}{2} \cdot W L_{x}$ 
E. I. $\frac{d y}{d x}=-\frac{1}{6} w x^{3}+\frac{1}{4} \cdot W L_{x^{2}}+C 1$

Igualando E. I. $\frac{d y}{d x}=0$ verifica-se que $\mathrm{C} 1$; Porém para os pontos $\mathrm{A}$ e $\mathrm{B}$ sendo $\mathrm{C} 1$ e $\mathrm{C} 2$ como condições de contorno sendo para o ponto em $\mathrm{A}[\mathrm{x}=0, \mathrm{y}=0$ ] e para o ponto em $\mathrm{B}$ $\left[\mathrm{x}=\mathrm{L}, \mathrm{y}=0\right.$ ], então para $\mathrm{x}=0, \mathrm{y}=0 \log \mathrm{C} 2=0$ e para $\mathrm{x}=\mathrm{L}, \mathrm{y}=0 \log \mathrm{C} 1=\frac{1}{24} W \cdot L^{3}$.

$$
C 1=\frac{1}{6} w x^{3}-\frac{1}{4} \cdot W L_{x^{2}} \quad \therefore \quad C 1=-\frac{1}{24} \cdot W L^{3}
$$

Integrando a segunda vez temos o deslocamento.

$$
\begin{aligned}
& \text { E.I.y }=-\frac{1}{24} W x^{4}+\frac{1}{12} W L x^{3}+C 1 x+0 \\
& \text { E. I. } \mathrm{y}=-\frac{1}{24} W x^{4}+\frac{1}{12} W L x^{3}-\frac{1}{24} \cdot W L^{3} x \\
& \mathrm{y}=\frac{W}{E . I}-\frac{1}{24} x^{4}+\frac{1}{12} L x^{3}-\frac{1}{24} \cdot L^{3} x \\
& \mathrm{y}=\frac{W}{24 \cdot E \cdot I}\left(-x^{4}+2 \cdot L x^{3}-L^{3} x\right) \\
& \mathrm{y}=\frac{W}{24 \cdot E \cdot I}\left(-\left(\frac{L}{2}\right)^{4}+2 \cdot L\left(\frac{L}{2}\right)^{3}-L^{3}(L / 2)\right) \\
& \mathrm{y}=\frac{W}{24 \cdot E \cdot I}\left(-\frac{L^{4}}{16}+2 . L \frac{L^{3}}{8}-L^{3} \frac{L}{2}\right)=-\frac{5 W L^{4}}{384 E I}
\end{aligned}
$$

Logo, o Deslocamento ou Flexão máxima da linha elástica resulta em

$$
\begin{aligned}
& \frac{-5\left(W L^{4}\right)}{384 . E . I}=\frac{\frac{-5\left(W L^{4}\right)}{384 \cdot E \cdot \frac{\left(b \cdot h^{3}\right)}{12}}}{384 \times 2,1 \cdot 10^{11} \times\left(\left(15 \times 22^{3}\right) / 12\right)}=-0,0081 \mathrm{~mm}
\end{aligned}
$$

onde:

$W=$ Densidade de carga ou força

( $\mathrm{KN} / \mathrm{m})$

$L=$ Distância de atuação da força

$E=$ Módulo de elasticidade ou módulo de Young ( $\mathrm{Pa})$

$I=$ Momento de inércia

$\left(\mathrm{mm}^{4}\right)$

Utilizando-se ainda do $E F C$ tem-se a deflexão da Matriz analisada.

$\delta=\frac{E F C \cdot L^{3}}{192 \cdot E \cdot I}$ 


$$
\delta=\frac{83200 \cdot 80^{3}}{192.210000 \cdot\left(\left(15.22^{3}\right) / 12\right)}=\frac{83200 \cdot 512000}{192 \cdot 210000.13310}=0,079 \mathrm{~mm}
$$

A deformação lateral do cume de corte foi considerada como deflexão chegando no valor abaixo:

$\delta_{1}=\frac{83200 \cdot 60^{3}}{192 \cdot 210000 \cdot\left(\left(22 \cdot 15^{3}\right) / 12\right)}=\frac{17971200000}{192 \cdot 210000 \cdot 6187,5}=0,072 \mathrm{~mm}$

Considerando a Matriz apoiada sobre placas temos a deflexão:

$\delta_{2}=\frac{P \cdot h}{A \cdot E}=\frac{83200 \cdot 22}{(80.15) \cdot 210000}=0,0072 \mathrm{~mm}$

\section{DADOS PARA CONFIGURAÇÃO DO SOFTWARE}

Os casos mais questionáveis são, o quanto suportam os supostos materiais em suas solicitações, Tensão de Escoamento, Tensão Máxima de Cisalhamento, Tensão de Escoamento, Tensão de Tração ou Compressão, analisados com os valores obtidos através das simulações, ou seja, se a peça deforma e o quanto deforma; as variáveis mais utilizadas (requeridas) estão melhor esplanadas abaixo:

\section{RESISTÊNCIA MAXIMA À TRAÇÃO/COMPRESSÃO (Tensile Ultimate trength/Compressive $(\mathrm{Pa})$ )}

Resultados referentes aos ensaios de flexão para 4-pontos e impacto para os aços D6 e D2, nas condições de temperado e revenido com e sem nitretação.

Os casos mais questionáveis são, o quanto suportam os supostos materiais em suas solicitações, Tensão de Escoamento, Tensão Máxima de Cisalhamento, Tensão de Escoamento, Tensão de Tração ou Compressão, analisados com os valores obtidos através das simulações, ou seja, se a peça deforma e o quanto deforma; as variáveis mais utilizadas (requeridas) estão melhor esplanadas abaixo: 
Figura 3 - Valores de Módulo de Ruptura obtidos em ensaio de flexão 4-pontos para os aços D2 e D6 temperados e revenidos com e sem a aplicação do processo de nitretação

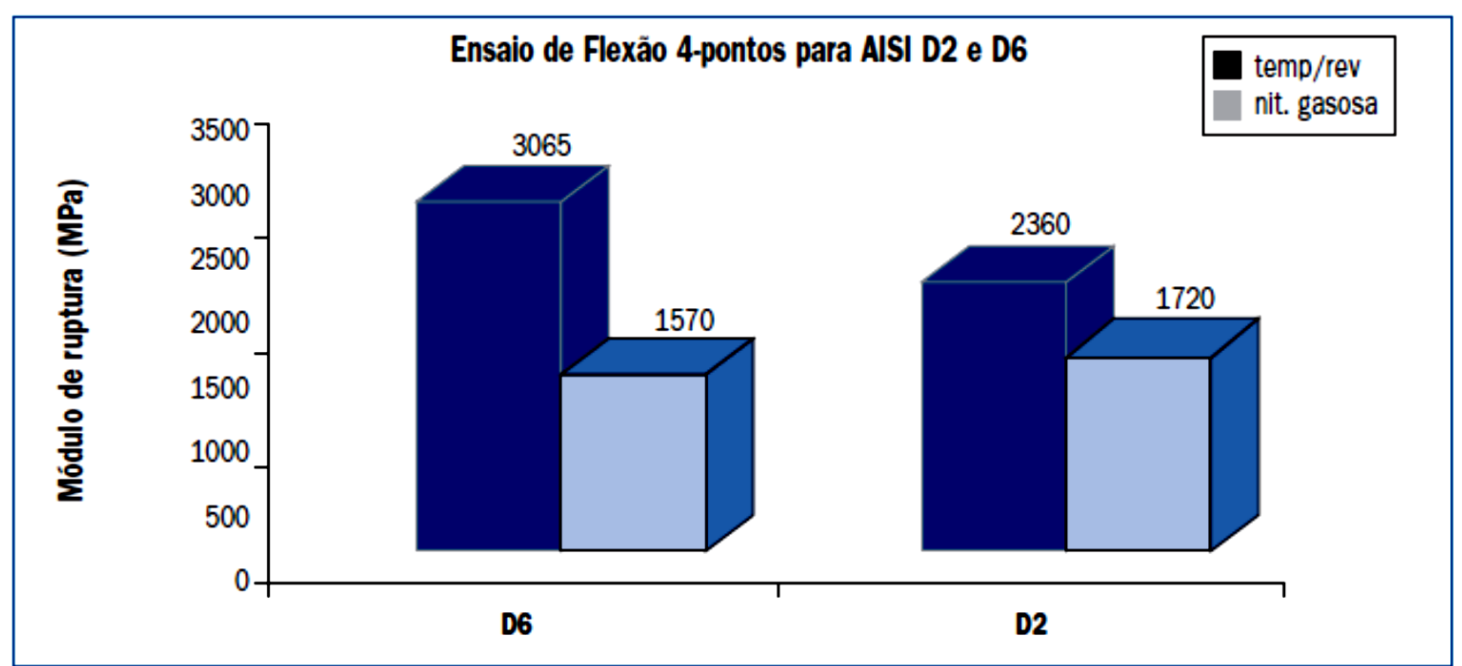

Fonte. http://editorarevistas.mackenzie.br/index.php/rmec/article/view/1960 (Acesso em: 19 mar. 2018).

RESISTÊNCIA À TRAÇÃO/COMPRESSÃO (Tensile Yield trength/Compressive Yield Strength $(\mathbf{P a}))$

Uma relação aproximada entre a Dureza e a Resistência à Tração para diversos materiais, onde as Durezas Brinnell do material podem ser convertidas conforme dados da tabela.

Tabela 1 Representação da Tabela do fator $\mathbf{K}$ para outros Metais.

\begin{tabular}{|l|l|l|l|l|l|}
\hline Material & Fator K & Material & Fator K & Material & Fator K \\
\hline Aço carbono & 0,36 & Bronze laminado & 0,22 & Ligas Al $-\mathrm{Mg}$ & 0,44 \\
\hline Aço liga & 0,34 & Bronze fundido & 0,23 & Ligas Mg & 0,43 \\
\hline Cobre e Latão & 0,40 & Ligas Al $-\mathrm{Cu}-\mathrm{Mg}$ & 0,35 & $\begin{array}{l}\text { Alumínio } \\
\text { fundido }\end{array}$ & 0,26 \\
\hline
\end{tabular}

Fonte. Adaptação Autor http://www.tecem.com.br/wp-content/uploads/2013/03/MU27

$\sigma B=K . H B \therefore \sigma B=0,36.658=236,9 \frac{\mathrm{Kgf}}{\mathrm{mm} 2}=2368,9 \mathrm{MPa}$

onde:

$\sigma B=$ Resistência a tração $\left(\mathrm{kgf} / \mathrm{mm}^{2}\right)$

$K=$ Fator para o cálculo da resistência à tração (Tabela)

$H B=$ Dureza após ensaio Brinnell $(62 \mathrm{HRC}=658 \mathrm{HB})$

MÓDULO DE ELASTICIDADE (Pa) 
Módulo de Elasticidade (Módulo de Young) é uma medida de rigidez, dado importante em aplicações onde a quantidade de distorção deve ser pequena, onde o valor oscila entre 194 e 238,77 GPa.

O valor indicado para a Resistência a Compressão $\mathrm{mm}^{2}$ com dureza de 62 HRC é de 2210 MPa ou $2210 \mathrm{~N} / \mathrm{mm}^{2}$.

\section{MÓDULO DE CISALHAMENTO Shear Modulus (Pa)}

Para materiais isotropicos o Módulo de Cisalhamento tem sua relação entre Módulo de Young eo Módulo de Cisalhamento e a razão de Poisson, que são relacionados por $\mathrm{E}=$ 2G . (1+v) [9]; Conclui-se que o Modulo de Young (Módulo de Elasticidade) pode ser admissível em até 202,8 GPa, o qual o software para assume o Modulo de Cisalhamento em $78 \mathrm{GPa}$.

$v=(E / 2 G)-1$ ou, $\mathrm{E}=2 \mathrm{G} .(1+\mathrm{v})$.

$v+1=\frac{E}{2.78} \quad 1+0,30=\frac{E}{156} \quad \mathrm{E}=1,30.156 \quad \mathrm{E}=202,8 \mathrm{GPa}$

A razão de Poisson aponta o $\mathbf{G}$ equivalente e aproximadamente a $\mathbf{0 , 4 . E}$;

$G=0,4^{*} E \quad G=0,4^{*} 202,800 \mathrm{MPa} \quad G \approx 81120 \mathrm{MPa}$

Então estimado a deformação conclui-se da tensão aplicada.

$\mathrm{E}=\sigma / \varepsilon \quad \therefore \quad \sigma=\mathrm{E} . \varepsilon$

Tabela 2 Tabela de comparativa de Deformações x Tensões.

\begin{tabular}{|c|c|c|c|}
\hline $\begin{array}{l}\text { Modulo } \\
\text { Young } \\
\text { (Elasticidade } \\
\text { ) }\end{array}$ & $\begin{array}{l}\text { Deform } \\
\text { ação } \\
\text { (mm) }\end{array}$ & $\begin{array}{l}\text { Condição de } \\
\text { apoio da Matriz }\end{array}$ & $\begin{array}{l}\text { o aplicado } \\
\text { (MPa) }\end{array}$ \\
\hline 202800 & 0,079 & Sob placa & 16021,20 \\
\hline 202800 & 0,072 & $\begin{array}{l}\text { Calço prox. Pino } \\
\text { de guia }\end{array}$ & 14601,60 \\
\hline 202800 & 0,0072 & $\begin{array}{l}\text { Sob calço semi } \\
\text { fechado }\end{array}$ & 1460,16 \\
\hline 202800 & 0,0081 & $\begin{array}{l}\text { Sob calço } \\
\text { fechado }\end{array}$ & 1642,68 \\
\hline
\end{tabular}

Fonte. O Autor

sendo:

$\mathrm{G}=$ Módulo de Cisalhamento

$v=$ Coeficiente de Poisson (adimensional)

$\mathrm{E}=$ Módulo de Elasticidade ou Módulo de Young (MPa)

$\sigma=$ Tensão aplicada (MPa) 
$\varepsilon=$ Deformação Elástica Longitudinal corpo de prova (adimensional).

\section{MÉTODOS}

As deformações, Resistências e forças foram avaliadas por simulações dentro do software Ansys.

\section{SIMULAÇÃO NO ANSYS DA TENSÃO DE VON MISES.}

Figura 4- Representação da Tensão Max. Principal no ambiente do software ANSYS

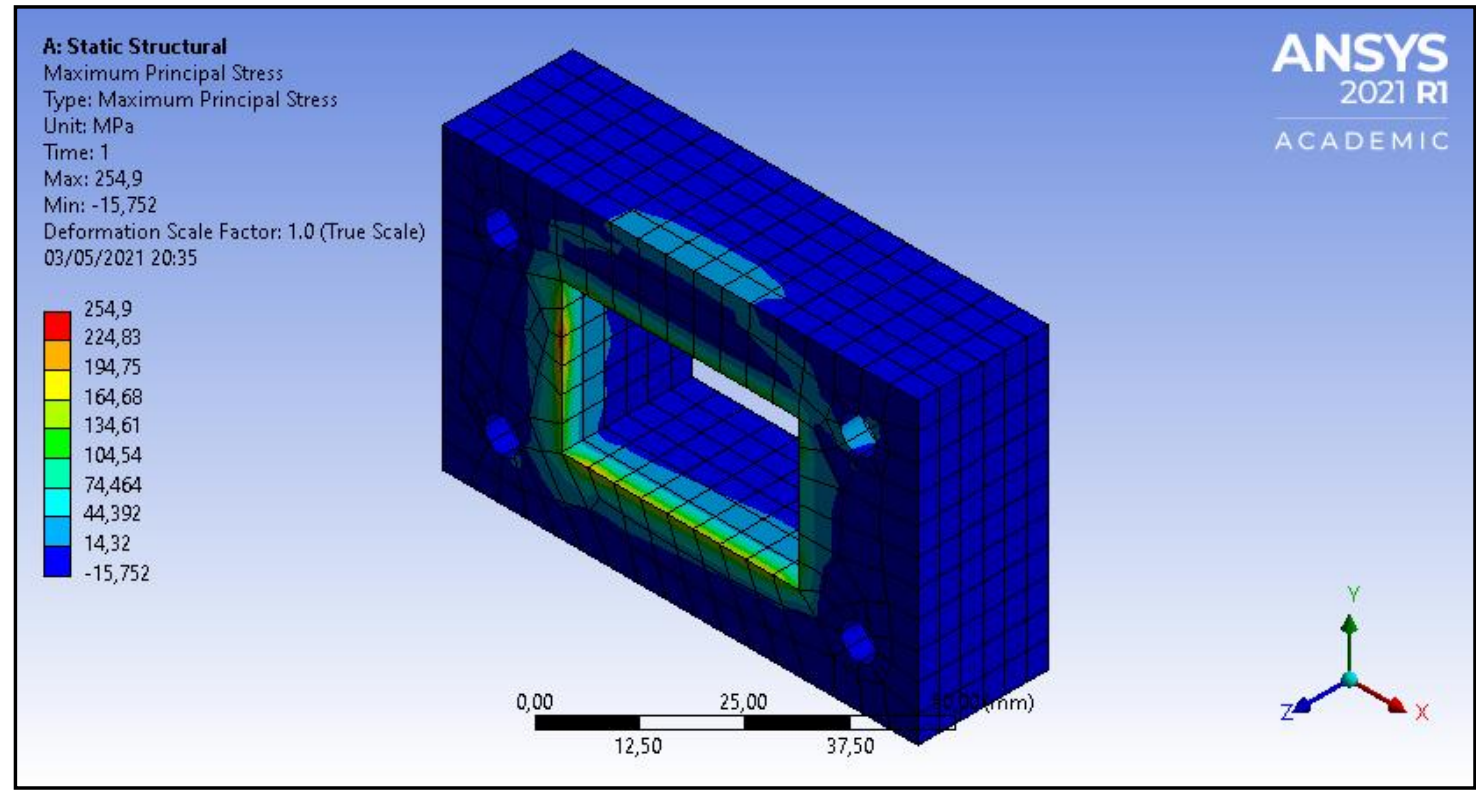

Fonte. Adaptação do Autor Conforme ensaio no Software ANSYS

Figura 5- Representação da Tensão Media Principal no ambiente do software ANSYS

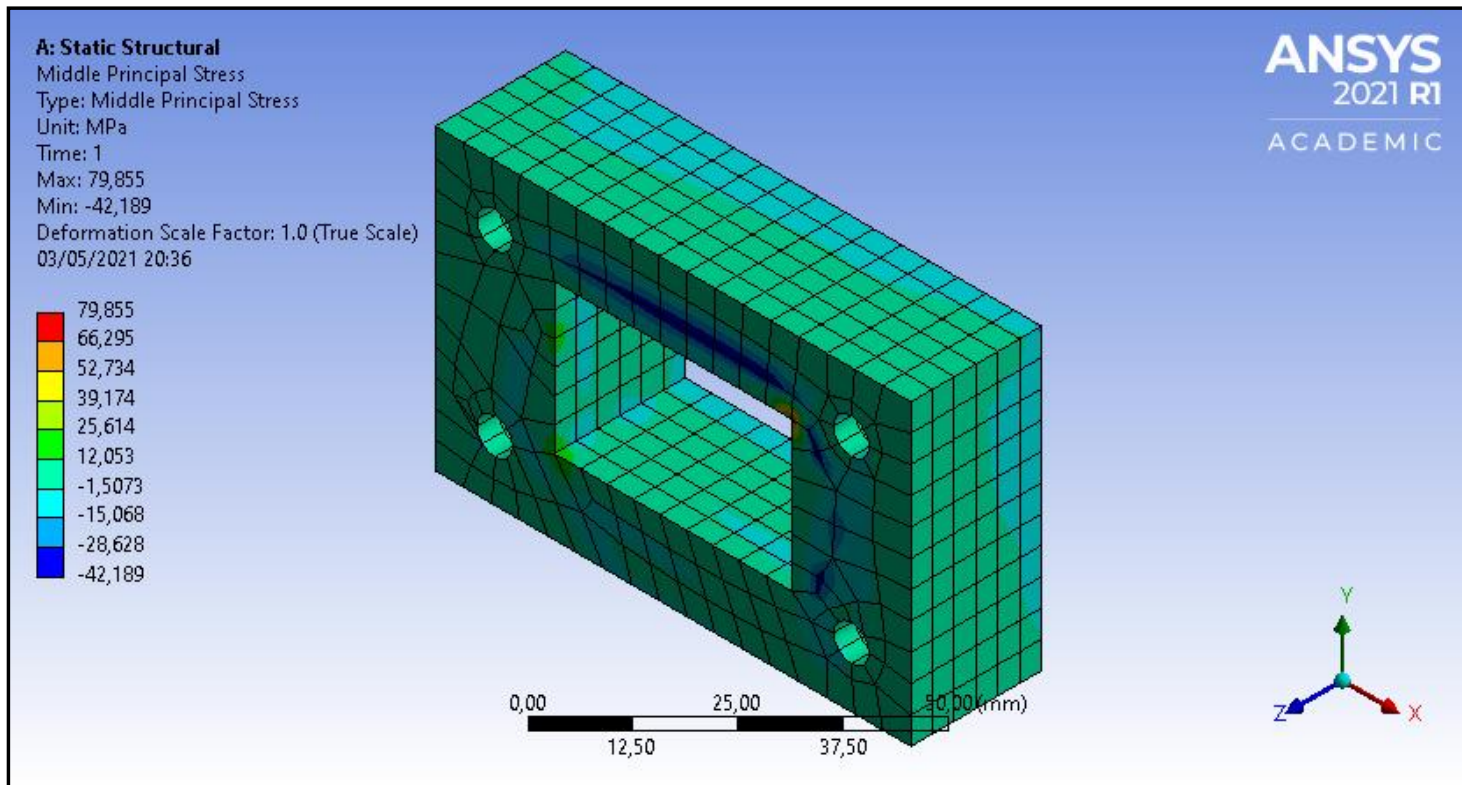

Fonte. Adaptação do Autor Conforme ensaio no Software ANSYS

Figura 6 - Representação da Tensão Minima Principal no software ANSYS 


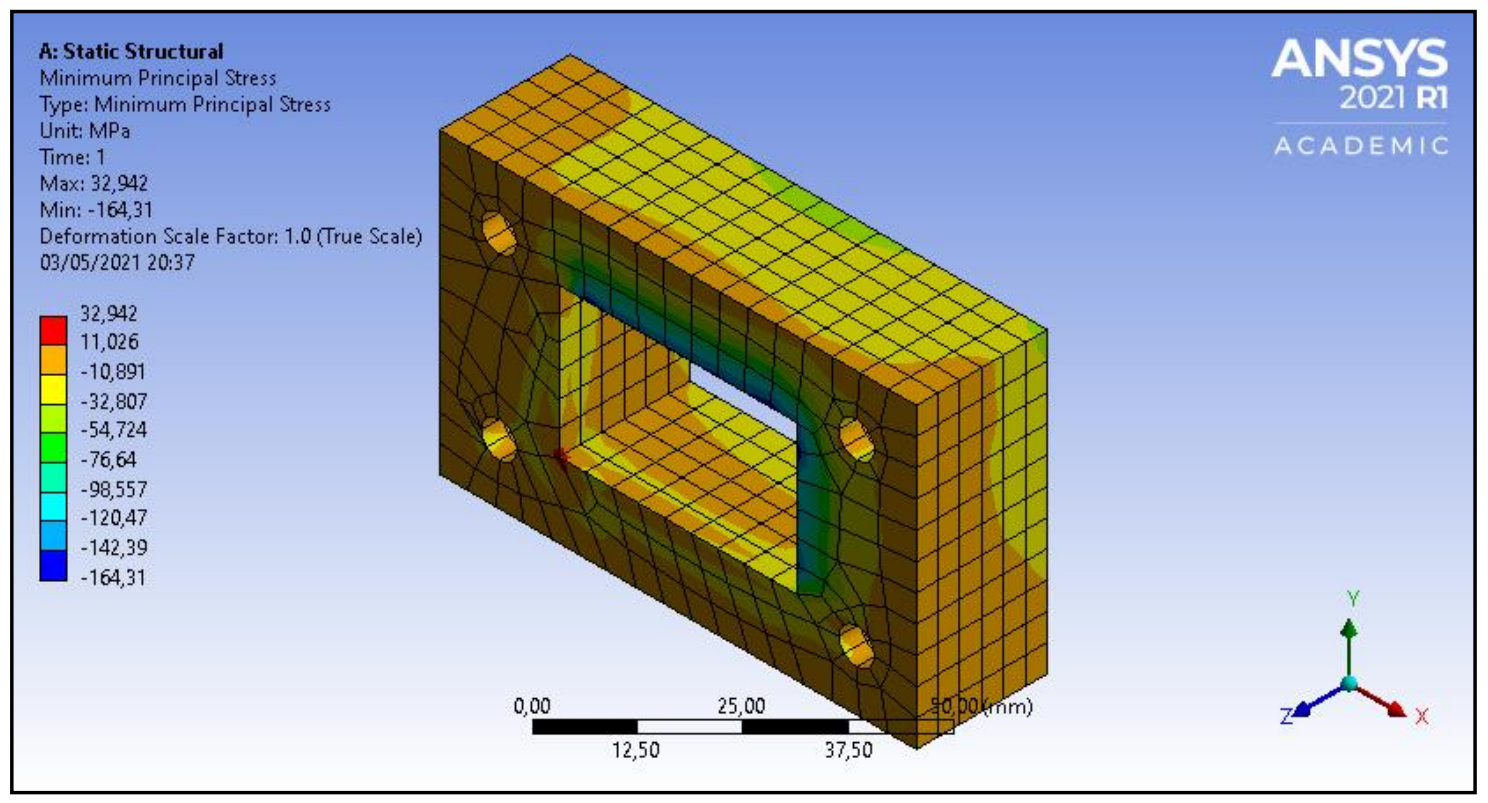

Fonte. Adaptação do Autor Conforme ensaio no Software ANSYS

Figura 7 - Representação da Tensão equivalente de Von Mises no software ANSYS

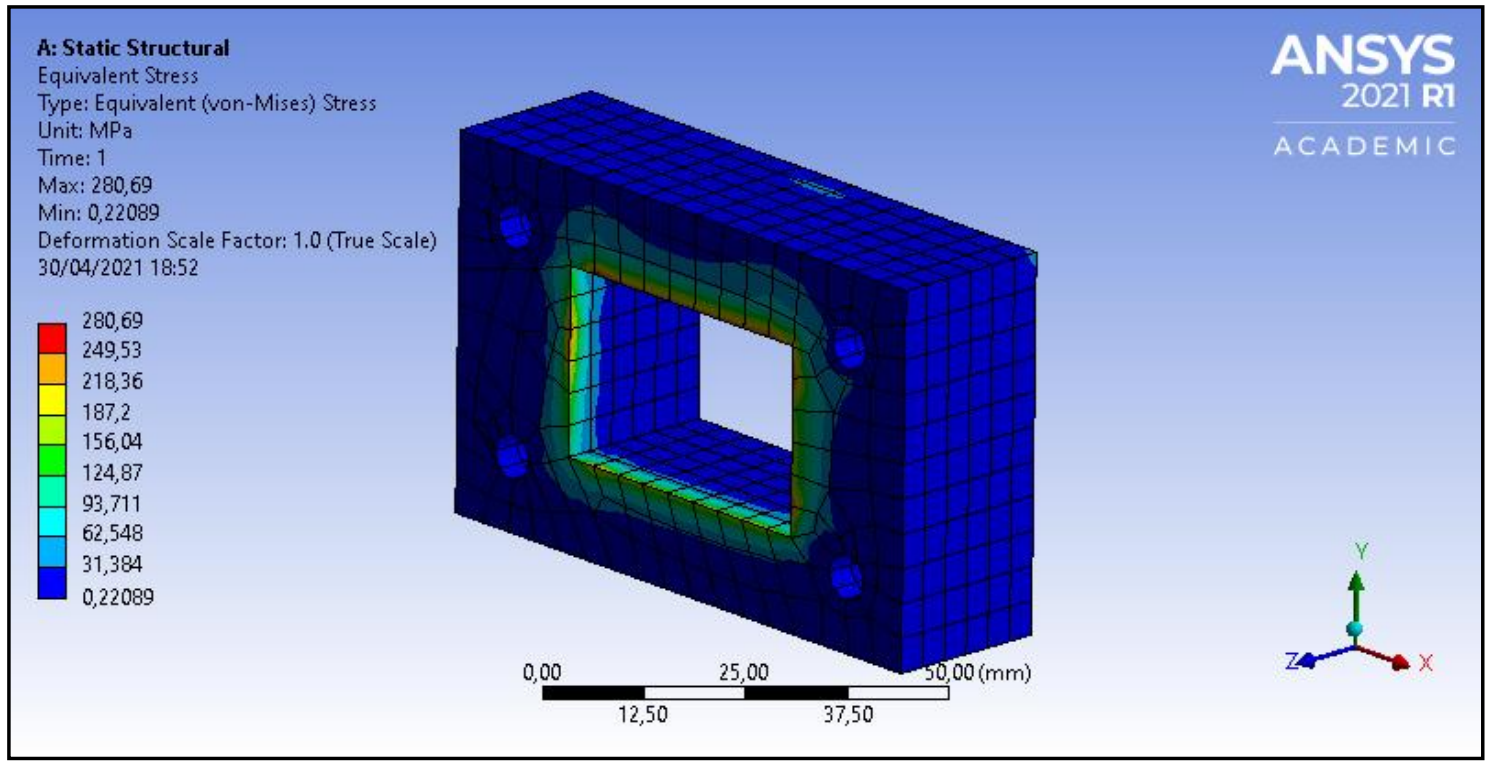

Fonte. Adaptação do Autor Conforme ensaio no Software ANSYS

A simulações das Figura 04, 05, 06 e 07 mostram as Tensões Máxima, Média e Mínima, que neste estudo os resultados serão utilizados para compor cálculo da Tensão Equivalente de Von Mises.

$\sigma_{e}=\left[\frac{\left(\sigma_{1}-\sigma_{2}\right)^{2}+\left(\sigma_{2}-\sigma_{3}\right)^{2}+\left(\sigma_{3}-\sigma_{1}\right)^{2}}{2}\right]^{\frac{1}{2}}$

$\sigma_{e}=\left[\frac{(254,900-79,855)^{2}+(79,855-32,942)^{2}+(32,942-254,900)^{2}}{2}\right]^{\frac{1}{2}}$ 
$\sigma_{e}=\left[\frac{(175,045)^{2}+(46,913)^{2}+(-221,958)^{2}}{2}\right]^{\frac{1}{2}} \therefore \sigma_{e}=202,62 \mathrm{MPa}$

A simulação pelo método numérico resultou em 202,62 MPa enquanto a simulação gráfica da figura 07 mostra a Tensão máxima de Von Mises de 280,69 MPa. Embora seja o critério apliacdo em materiais dúcteis.

Portanto a Tensão de Falha $\sigma_{\mathrm{f}}$ :

$\sigma_{\mathrm{f}}=\sigma_{\mathrm{e}} / \sqrt{3} \quad \therefore \quad \sigma_{\mathrm{f}}=280,69 / \sqrt{3} \quad \therefore \quad \sigma_{\mathrm{f}}=120,49 \mathrm{MPa}$.

Enquanto o Limite de Escoamento $\sigma_{\mathrm{L}}$ :

$\sigma_{\mathrm{L}}=\sigma_{\mathrm{f}} / 0,577 \quad \therefore \quad \sigma_{\mathrm{L}}=120,49 / 0,577 \quad \therefore \quad \sigma_{\mathrm{L}}=208,82 \mathrm{MPa}$

Onde a Tensão de Cisalhamento puro $\boldsymbol{\tau}$ como sendo $0,577 * \sigma_{\text {limite }}$

$\boldsymbol{\tau}=0,577 * 3065 \mathrm{MPa} \quad \boldsymbol{\tau}=1770,65 \mathrm{MPa}$.

\section{SIMULAÇÃO NO ANSYS DA DEFORMAÇÃO x FLEXÃO.}

Figura 8 - Representação da Deformação Elastica no software ANSYS

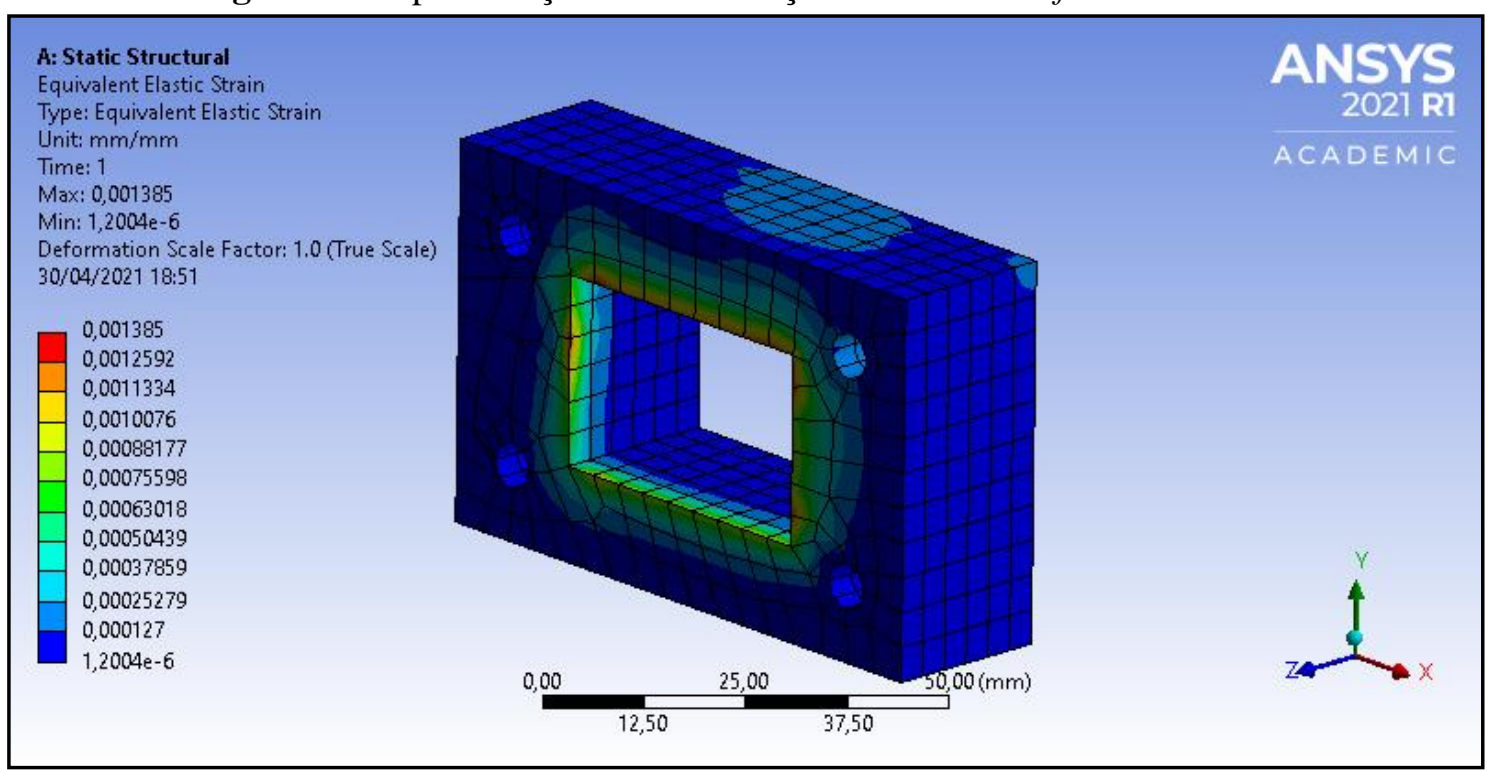

Fonte. Adaptação do Autor Conforme ensaio no Software ANSYS

A Deformação Elástica Equivalente (Deformação Elástico), utilizando da força de corte normal (perpendicular a face da matriz) de $10400 \mathrm{Mpa}$; como indica abaixo.

$\varepsilon_{e}=\frac{1}{1+v} \quad\left\{\frac{1}{2}\left[\frac{\left(\varepsilon_{1}-\varepsilon_{2}\right)^{2}+\left(\varepsilon_{2}-\varepsilon_{3}\right)^{2}+\left(\varepsilon_{3}-\varepsilon_{1}\right)^{2}}{2}\right]\right\}^{\frac{1}{2}}$ 


$$
\begin{gathered}
\varepsilon_{e}=\frac{1}{1+0,30}\left\{\frac{1}{2}\left[\frac{(0,00637-0,01083)^{2}+(0,01083-0,00692)^{2}+\left(0,00692-0,00637_{1}\right)^{2}}{2}\right]\right\}^{\frac{1}{2}} \\
\varepsilon_{e}=0,7692\left\{\frac{1}{2}\left[\frac{(-0,00446)^{2}+(0,00391)^{2}+(0,00055)^{2}}{2}\right]\right\}^{\frac{1}{2}} \\
\varepsilon_{e}=0,7692\left\{\frac{1}{2}\left[\frac{(-0,00446)^{2}+(0,00391)^{2}+(0,00055)^{2}}{2}\right]\right\}^{\frac{1}{2}} \\
\varepsilon_{e}=0,00163
\end{gathered}
$$

Figura 9 - Representação da Flexão pelo Modulo de Rigidez no software ANSYS

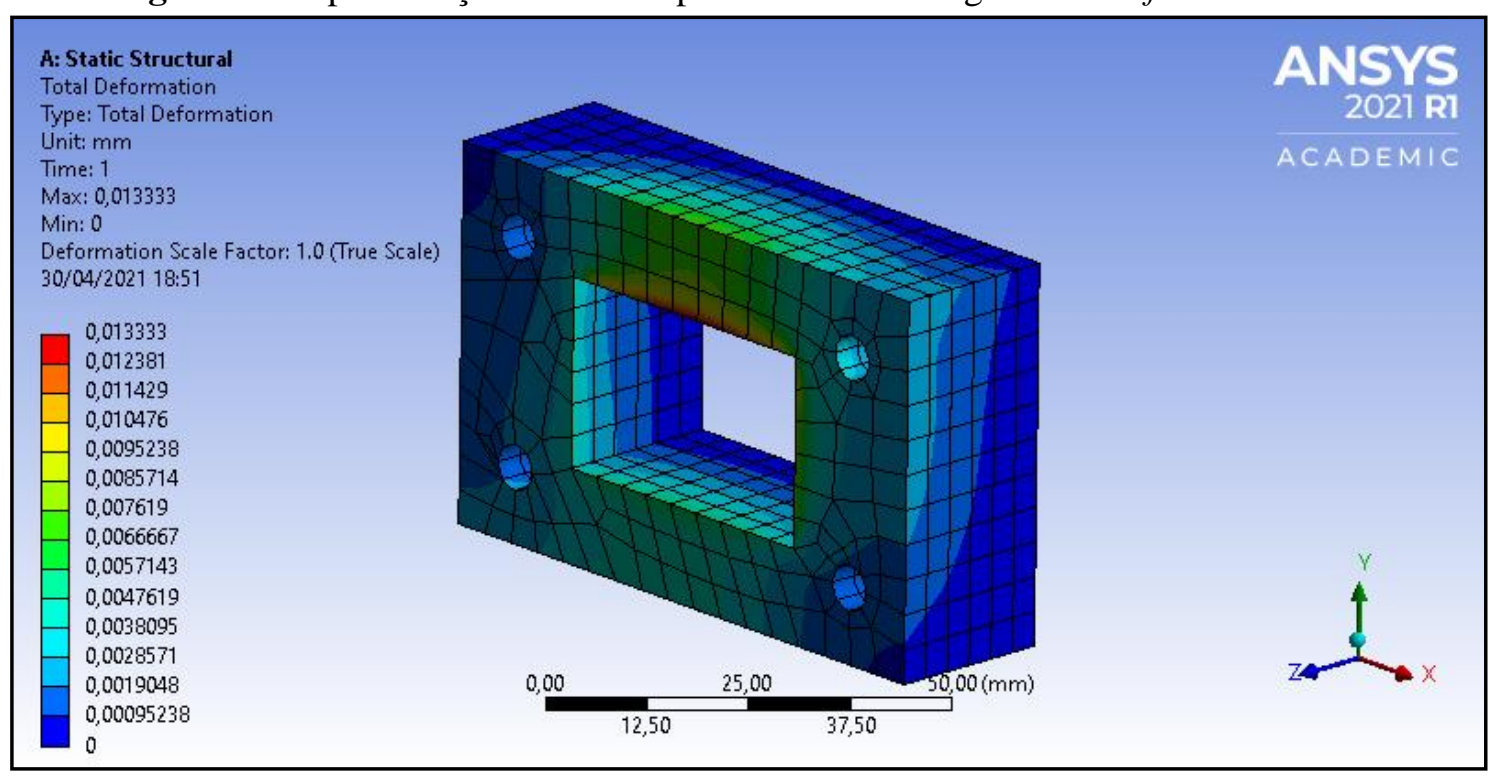

Fonte. Adaptação do Autor Conforme ensaio no Software ANSYS

A característica desta deformação ficou então entre $0,00138 \mathrm{~mm}$ e $0,00163 \mathrm{~mm}$.

Enquanto a simulação pelo Módulo de Rigidez (Elasticidade ou Young) mostrou uma deformação total máxima de $0,0133 \mathrm{~mm}$. 


\section{SIMULAÇÃO NO ANSYS DA TENSÃO DE CISALHAMENTO.}

Figura 10 - Representação do Modulo decisalhamento no software ANSYS

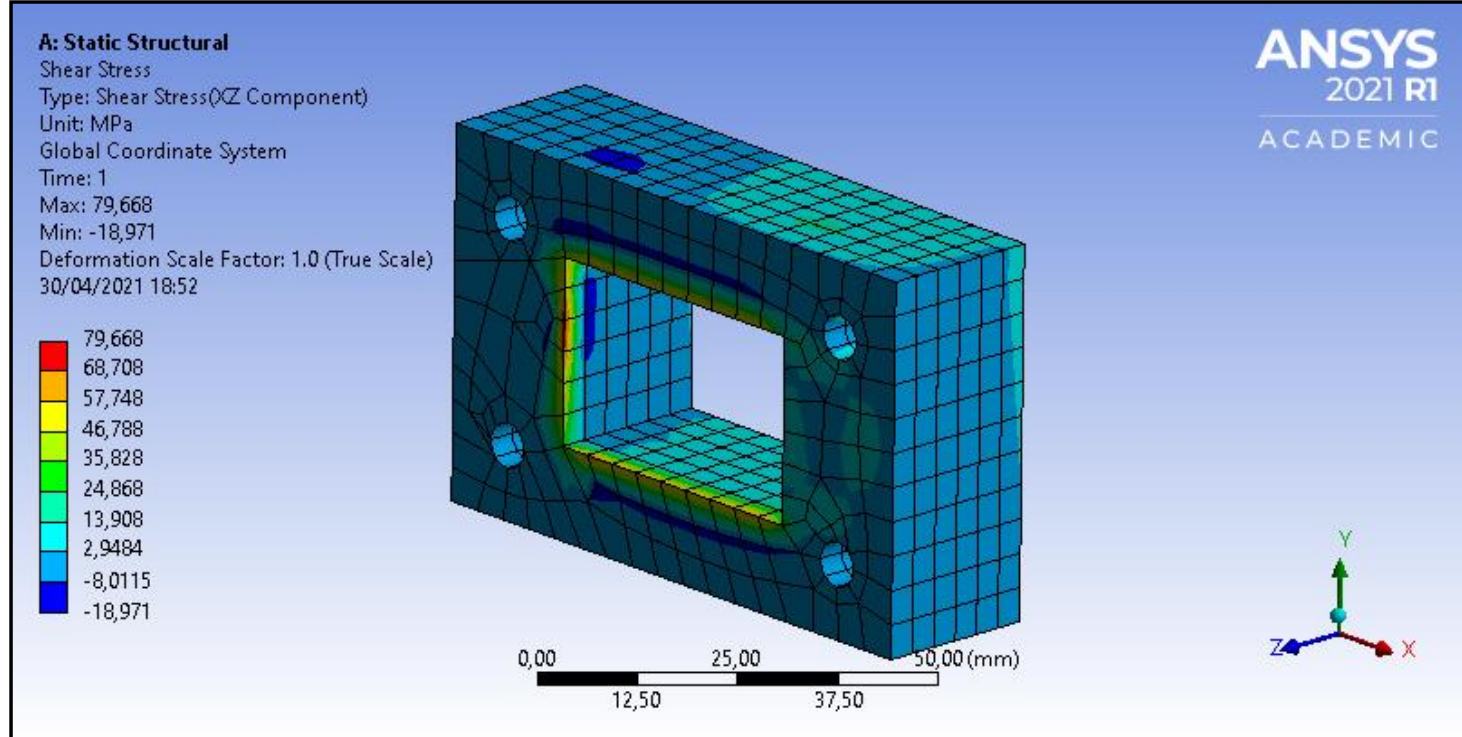

Fonte. Adaptação do Autor Conforme ensaio no Software ANSYS

A Tensão do Modulo de Cisalhamento está próximo de 79,668 MPa nas direções x,z enquanto que nas direções y,z 99,946 MPa e 77,117 MPa para as direções xy,

\section{SIMULAÇÕES NO ANSYS PARA DEFLEXÃO NAS DIREÇÕES X,Y,Z.}

Figura 11 - Representação da Deflexão na direção X no software ANSYS

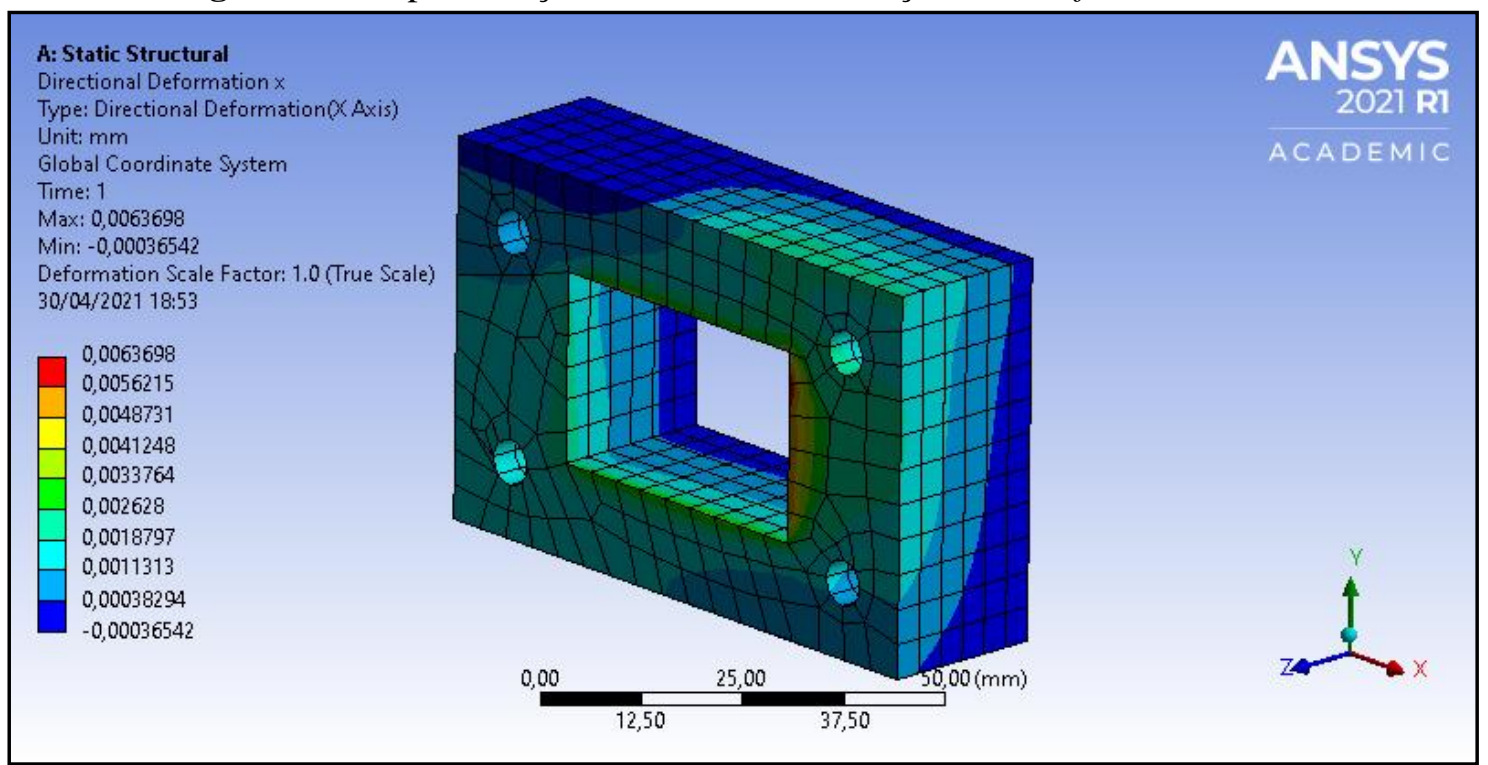

Fonte. Adaptação do Autor Conforme ensaio no Software ANSYS 
Figura 12 - Representação da Deflexão na direção Y no software ANSYS

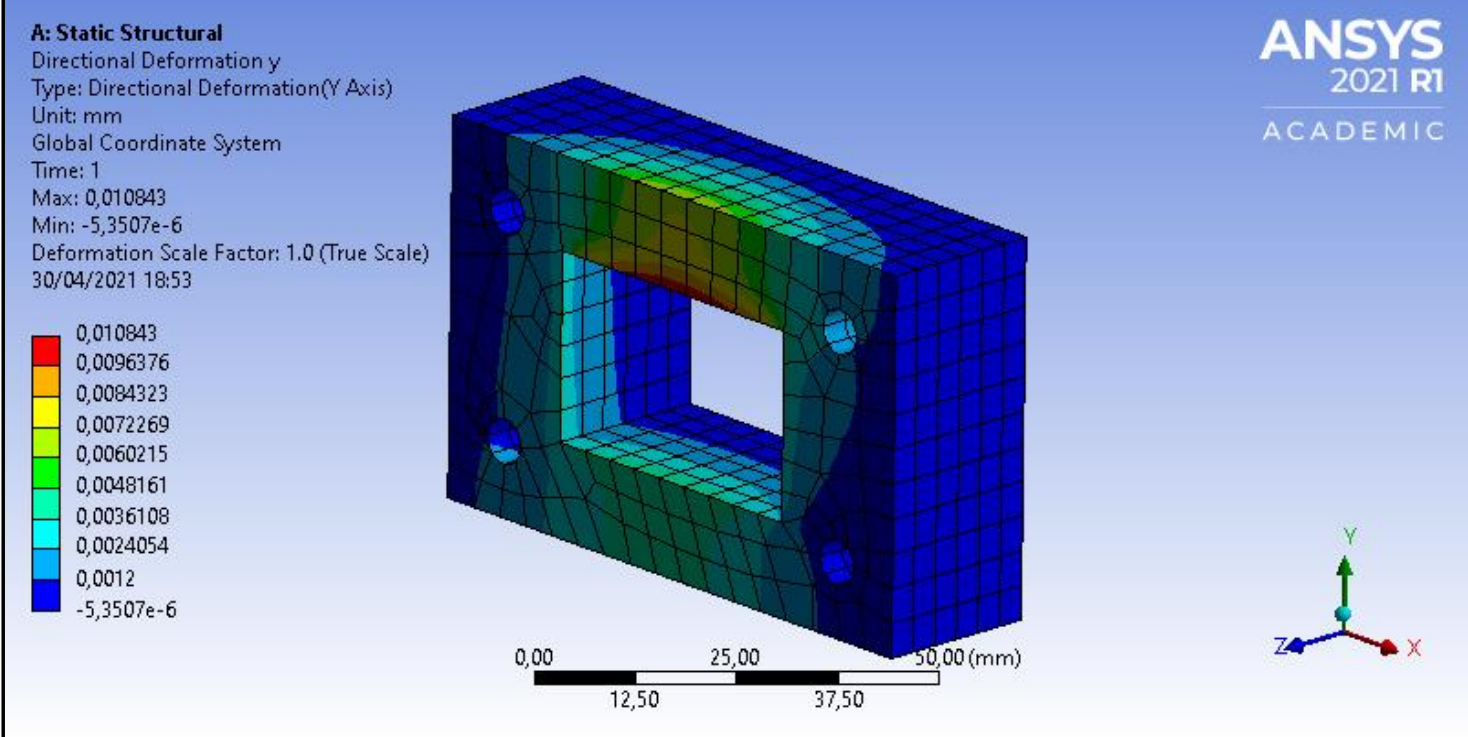

Fonte. Adaptação do Autor Conforme ensaio no software ANSYS

Figura 13 - Representação da Deflexão na direção Z no software ANSYS

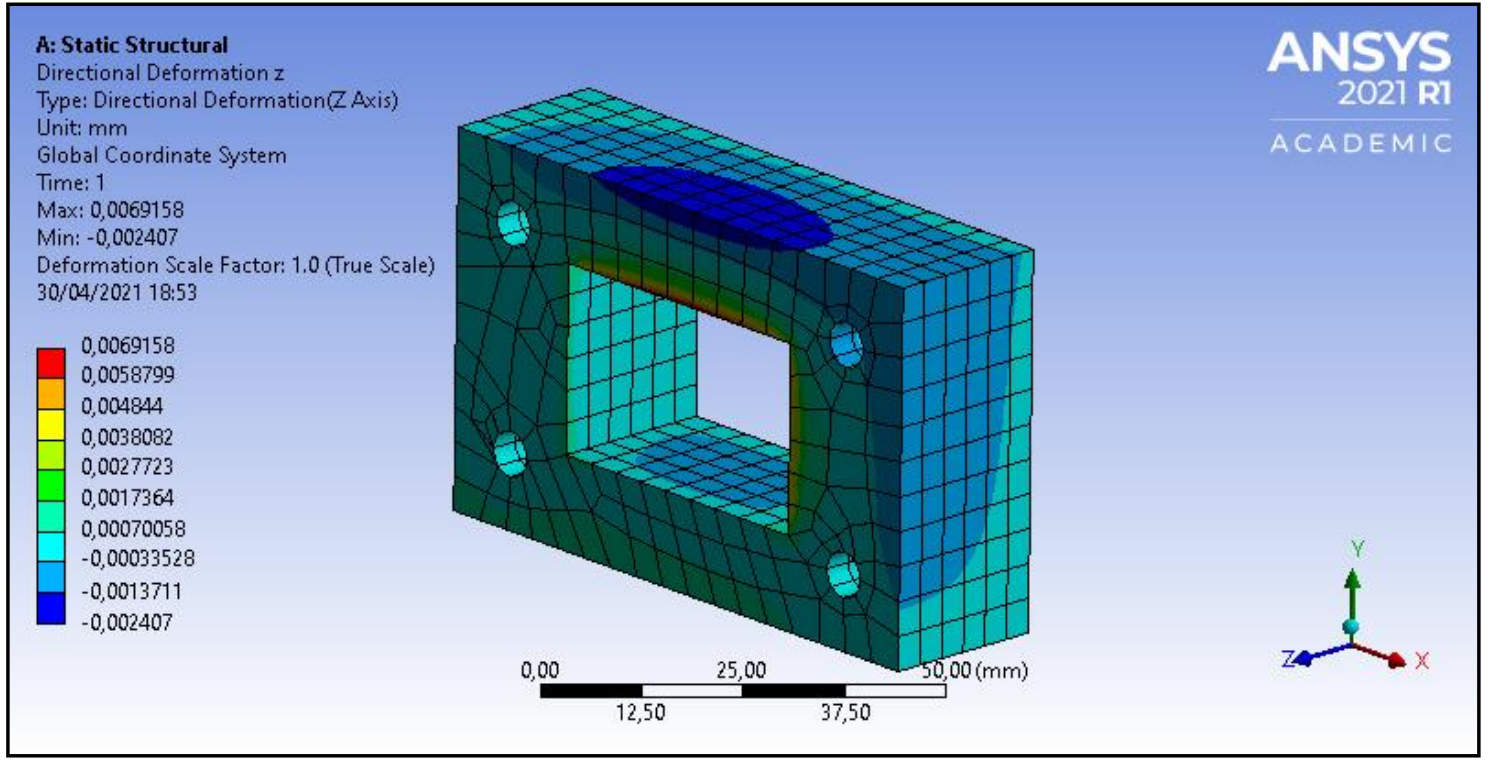

Fonte. Adaptação do Autor Conforme ensaio no software ANSYS

Os deslocamentos oriundos da força de corte de 10400MPa, aplicada ao longo dos cumes de corte, onde são observadas as máximas na ordem em x $(0.00637 \mathrm{~mm})$, y $(0,01084 \mathrm{~mm})$ e z $(0,00692 \mathrm{~mm})$ sendo as deformações médias de $0,00804 \mathrm{~mm}$;

\section{DISCUSSÃO}

Ao longo do trabalho foi percebido que o processo pode ser aceito como decorreu neste trabalho, porem sugere-se que, sempre que possível revalidar os dados com novos ensaios afim de encontrar valores mais proximos do material fisico existente para a confecçao dos ferramentais. 
Uma vez definida a espessura da matriz, outra caracteristica relevante esta em obter bases de apoio (calços) na menor distancia entre o vão bem proximo da saida dos cavacos sem que possivel.

\section{CONCLUSÃO}

A qualidade deste trabalho, pode também ser explorada por vários outros softwares voltados para Elementos Finitos, entretanto ficará para uma segunda ordem, bem como um estudo mais aprofundado das propriedades mecânicas dos materiais em aço D6 (VC131) na dureza de $62 \mathrm{HRC}$, elencando assim o ANSYS como uma ferramenta apropriada e de multiuso com uma precisão muito boa.

O auxílio computacional é de suma importância quando utiliza se de modo ordenado, visando a redução de custos com protótipos e experiências empíricas; uma vez utilizandose do método convencional seriam necessários dois ferramentais (estampos), haja visto que a remoção do material na espessura pode ser encarada como um ensaio destrutivo e oneroso.

O investimento com relação a softwares e mão de obra especializada tornam-se irrelevantes quando comparados com recursos e tempos aplicados de formas empíricas abrangendo então diferentes áreas de especializações.

Tanto por simulação ou por cálculos numérico, os deslocamentos têm em seus resultados uma pequena relatividade, estes deslocamentos estão diretamente atrelados aos ensaios dos materiais onde a maioria operam na zona da ruptura por tratar-se de materiais frágeis por dureza.

Tabela 03 - Tabela de comparativa da variação percentual dos resultados gerais

\begin{tabular}{|c|c|c|c|}
\hline Classificação do estudo & $\begin{array}{l}\text { Resultados } \\
\text { analíticos }\end{array}$ & $\begin{array}{l}\text { Resultados } \\
\text { computaciona } \\
\text { is }\end{array}$ & $\begin{array}{l}\Delta \\
\text { percentual }\end{array}$ \\
\hline Tensão de Tração & $625 \mathrm{n} / \mathrm{mm}^{2}$ & $700 \mathrm{n} / \mathrm{mm}^{2}$ & $12 \%$ \\
\hline Tensão de Cisalhamento & $78000 \mathrm{MPa}$ & 79,67 $\mathrm{MPa}$ & $2,14 \%$ \\
\hline $\begin{array}{l}\text { Tensão Equivalente de Von } \\
\text { Mises }\end{array}$ & $202,62 \mathrm{MPa}$ & $280,69 \mathrm{MPa}$ & $38,5 \%$ \\
\hline $\begin{array}{l}\text { Deformação Equivalente (Def. } \\
\text { Elástica) }\end{array}$ & $0,0016 \mathrm{~mm}$ & $0,0014 \mathrm{~mm}$ & $12,5 \%$ \\
\hline $\begin{array}{l}\text { Deformação Total (Def. não } \\
\text { Recuperável) }\end{array}$ & $0,0760 \mathrm{~mm}$ & $0,0133 \mathrm{~mm}$ & $82,5 \%$ \\
\hline Módulo de cisalhamento & $78000 \mathrm{MPa}$ & 79,7 MPa & $1,37 \%$ \\
\hline Coeficiente de Poisson & 0,38 & 0,30 & $21,05 \%$ \\
\hline Deformação na Direção X & $0,0064 \mathrm{~mm}$ & $0,0790 \mathrm{~mm}$ & $1134,37 \%$ \\
\hline
\end{tabular}




\begin{tabular}{|l|l|l|l|}
\hline Deformação na Direção Y & $0,0108 m m$ & $0,0720 \mathrm{~mm}$ & $566,67 \%$ \\
\hline Deformação na Direção Z & $0,0069 \mathrm{~mm}$ & $0,0720 \mathrm{~mm}$ & $943,48 \%$ \\
\hline Deformação na Direção Y & $0,0081 \mathrm{~mm}$ & $0,0108 \mathrm{~mm}$ & $33,33 \%$ \\
\hline
\end{tabular}

Fonte: O Autor

As análises dos resultados acerca dos cálculos numéricos demonstraram-se satisfatórios em relação ao modelo computacional dando a segurança necessária e satisfatória para o estudo e validação do processo.

O cálculo a respeito da espessura da Matriz, demonstraram-se eficientes com a comprovação por simulação via $\mathrm{MEF}$.

As variações por parte de literaturas e sites especializados em materiais, não interferiram no desempenho da Matriz.

As validações por simulação computacional tiveram em sua maioria resultados menores em relação a aqueles obtidos por meios numéricos.

A comparação do estudo numérico eo computacional foram esclarecedoras, devido a segurança de ambos os processos proporcionaram.

\section{REFERÊNCIAS}

SILVEIRA, Fabrício Dreher; SCHAEFFER, Lírio. "Diretrizes para Projeto de Ferramenta de Estampagem". Partes 1, 2 e Final. Universidade Federal do Rio Grande do Sul, RS, 2008.

ASIF NIZAM, MORRISH KUMA, MAN MOHAN SONI, (2016). “Otimização de espessura de chapa e matriz Liberação da ferramenta Progressive Press usando o Finite Análise de Elementos e Rede Neural Artificial Técnica" Revista Internacional de Ciência e Pesquisa (IJSR) ISSN (Online): 2319-7064 Índice Copernicus Value (2013): 6,14 | Fator de Impacto (2014): 5.611 Volume 5 Edição 2, fevereiro de 2016. https://www.ijsr.net/archive/v5i2/NOV161498.pdf Acesso em: 08 jul. 2020.

KANCA, E., EYERCIOLGLU, O., KARAHAN, IH, GUNEN, A., GOV, K. (2016). "Efeitos da Velocidade de Supressão na Superfície de Cisalhamento do Aço Macio (St37)". Acta Physica Polonica A, 130 (1), 370-374. doi: 10.12693 / APhysPolA.130.370.

BRITO, O. Técnicas e Aplicações de Estampos de Corte. São Paulo: Hemus Editora Ltda., 1999, p.16-92.

OEHLER, G. e H. Kaiser. Schmitt Stanz-und Ziehwerzeuge. 7. ed., Springer Verlag, 1993.

VIVEK BARHATE, SACHIM MAH. AKALKAR, DR. A. KALE. "Design e Desenvolvimento de Matrizes para uma peça industrial - A Case Estudo" (ICEMEM), 2015. 
NICOLETTI, Renato Silva; PRESOTO, Adilson Eduardo. Equacionamento do método dos elementos finitos através da álgebra linear e suas aplicações na análise estrutural. Revista Brasileira de Iniciação Científica, v. 5, n. 3, p. 96-129, 2018.

JAN VATAVUK, ADAYR BÔRRO Jr., WALDEMAR A. MONTEIRO, EGBERTO GOMES FRANCO, Efeito da Nitretação Gasosa nas Propriedades Mecânicas dos Aços Ferramenta para Trabalho a Frio AISI D2 e D6, Disponível em:

http://editorarevistas.mackenzie.br/index.php/rmec/article/view/1960 Acesso em: 20 de dezembro de 2018.

CALLISTER, William D.; RETHWISCH, David G. Fundamentals of Materials Science and Engineering. London: Wiley, 2000.

Recebido em: 01/06/2021

Aprovado em: 25/06/2021

Publicado em: 30/06/2021 